Article

\title{
Construction and Transition Metal Oxide Loading of Hierarchically Porous Carbon Aerogels
}

\author{
Jintian Wang ${ }^{1}$, Xinyang Ruan ${ }^{1}$, Jiahao Qiu ${ }^{1}$, Hao Liang ${ }^{1}$, Xingzhong Guo ${ }^{1,2, * \mathbb{C} \text { and Hui Yang }}{ }^{1}$ \\ 1 State Key Laboratory of Silicon Materials, School of Materials Science and Engineering, Zhejiang University, \\ Hangzhou 310027, China; 21926060@zju.edu.cn (J.W.); 2009rxy@163.com (X.R.);

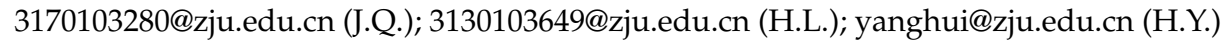 \\ 2 Pan Asia Microvent Tech (Jiangsu) Coporation \& Zhejiang University Micro-nano-porous Materials Joint \\ Research Development Center, Changzhou 213100, China \\ * Correspondence: msewj01@zju.edu.cn; Tel.: +86-571-8795-3313
}

Received: 20 August 2020; Accepted: 4 September 2020; Published: 11 September 2020

check for updates

\begin{abstract}
Hierarchically porous carbon aerogels (CAs) were prepared by organic condensation gelation method combined with atmospheric drying and pore-formation technology, followed by a carbonization process. With as-prepared CAs as substrate, the transition metal oxide nanoparticles loaded CAs composites $\left(\mathrm{MnO}_{2} / \mathrm{Mn}_{2} \mathrm{O}_{3} @ \mathrm{CA}\right.$ and Ni/NiO@CA) were achieved by means of liquid etching method combined with heat treatment, respectively. The catalyst, pore-forming agent and etching have important roles on the apparent density and pore structure of CAs. The hydrochloric acid (catalyst) significantly accelerates the gelation process and influences the size and distribution of macropores, whereas the addition of PEG2000 (pore-forming agent) and the etching of liquid solution leads to the formation of mesopore structure in CAs. Appropriate amounts of hydrochloric acid and PEG2000 allow the formation of hierarchically porous CAs with a BET surface area of $482.9 \mathrm{~m}^{2} \cdot \mathrm{g}^{-1}$ and a macropore size of $11.3 \mu \mathrm{m}$. After etching and loading, the framework of CAs is etched to become a mesoporous structure, and the transition metal oxide nanoparticles can be uniformly loaded in CAs. These resultant composites have promising application in super capacitor, electrocatalysis, batteries and other fields.
\end{abstract}

Keywords: carbon aerogel; hierarchically porous material; atmospheric drying; pore formation; transition metal oxide

\section{Introduction}

Carbon aerogel (CA), as a derivative of organic aerogel, is usually based on the polycondensation of resorcinol $(R)$ and formaldehyde $(F)$ [1]. It is a kind of porous amorphous carbon nano-material with a 3D interconnected structure, high porosity ( $>80 \%$ ), large specific surface area (usually $400 ~ 1100 \mathrm{~m}^{2} \cdot \mathrm{g}^{-1}$ before activation) and a particle diameter of around $3 \sim 20 \mathrm{~nm}$ [2]. CA is unique among other aerogels because of its electrical conductivity, corrosion resistance and chemical stability $[3,4]$, and has broad prospects in water purification [5,6], drug delivery system [7], heat insulation [8], super capacitor [9-11], carrier for catalyst [12,13], batteries [14] and other fields [15-17].

Compared with CA with a single pore size, hierarchical porous CA has more unique characteristics and properties derived from the micro-meso-macropore structure. The micropores and mesopores can provide higher surface area and pore volume to facilitate the easy access of electrolyte into the whole system [10,18-20], the exposable chemical active sites can improve reaction activity and reaction rate $[12,21]$, and the macropores can increase the porosity and decrease the density of the materials [22,23]. Moreover, the interconnected structure can also be used as transport channels to reduce path lengths for ion diffusion [11]. However, in the present CAs, the large volume shrinkage 
during the polymerization and drying process of a RF polymer inevitably occurs. Even if the micropore structure of gels could be maintained, the large pore structure in carbon aerogel disappears, which leads to a single pore size distribution and limits its application.

The pore structure of carbon aerogel is closely related to the sol-gel process [24]. Recently, there has been many attempts to regulate the pore structure by organic polymers [25]. Among the approaches, the pore-forming process is efficient approach to create the pores in the CAs [26]. In addition, supercritical/freeze drying are required to remove solvent to preserve the pore structure [27]. As is well known, supercritical/freeze drying is still not a cost-effective drying method due to the high requirements of equipment, complex operation, long experimental period, low output and high cost [28]. Many researchers have shifted their attention to the atmospheric drying method on the basis of retaining the three-dimensional porous network of the wet gel.

Herein, we report the preparation of hierarchical porous CAs by sol-gel combined with atmospheric drying and pore-formation technology. The effects of catalyst on the pore structure of carbon aerogel were investigated in detail. Two transition metal oxides were loaded on hierarchically porous CAs by a liquid etching process and heat treatment. More importantly, these composite materials can incorporate a secondary phase to improve the electrochemical activities of CAs, and the supporting structure stabilizes active components, which will extend the practical applications in energy storage for CAs.

\section{Results and Discussion}

\subsection{Controllable Preparation of Carbon Aerogels}

The synthesis strategy of transition metal oxides loaded CAs is schematically illustrated in Figure 1, and the typical SEM images are also provided to more intuitively demonstrate the synthesis process. Initial red and porous organic aerogels are simply synthesized via a sol-gol process accompanied by pore-formation technology, and the xerogel is mainly composed of pore-forming agent (PEG) and resorcinol-formaldehyde reaction product. Hierarchically porous carbon aerogels (CAs) are carbonized in argon atmosphere, and accordingly, the as-synthesized RF organic aerogels are in situ transformed into carbon aerogels with pore structure. Then, the transition metal oxide nanoparticles are loaded on the skeletons of CAs by etching and immersing, which results from high specific surface area of carbon aerogels. As a result, these composite materials have uniform and controllable morphology.

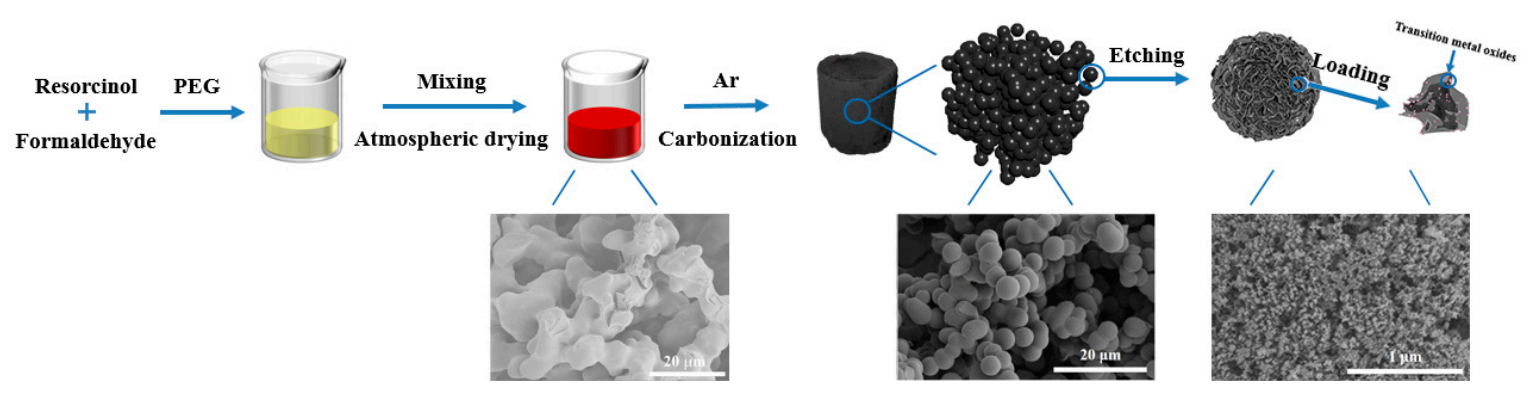

Figure 1. Schematic illustration of the synthesis process for transition metal oxides@CA.

In the preparation of organic aerogel, the use of catalyst has a significant effect on the organic addition polycondensation, thus controlling the appearance and microstructure of carbon aerogel. Hydrochloric acid is usually used as catalyst for the preparation of resorcinol-formaldehyde organic aerogel, and the acid environment can obviously promote the formation of RF organic gel. The effect of hydrochloric acid on the microstructure of carbon aerogel was investigated. With the increase of the amount of hydrochloric acid, the gelation time is shortened gradually, and the sample without hydrochloric acid has a gelation time as high as more than $4 \mathrm{~h}$. At $60^{\circ} \mathrm{C}$, the sample with $0.5 \mathrm{~mL}$ of hydrochloric acid can gelate within $1 \mathrm{~h}$. A supplementary experiment showed that if the same volume 
of $0.1 \mathrm{M}$ hydrochloric acid was completely replaced by water, the solution will completely gelate in $15 \mathrm{~min}$, accompanied by a severe exothermic phenomenon and a large number of pores on the surface of the xerogels.

The wet gels appear to be pale orange, and there is almost no volume contraction after atmospheric drying. The monolithic RF organic aerogel samples have strong strength, and the color changes to red with a dark oxidation zone on the surface. After carbonization, the samples does not shrink obviously, and the final carbon aerogel has a monolithic shape, high strength and small density. The volume density is $200 \sim 400 \mathrm{mg} \cdot \mathrm{cm}^{-3}$, which is much lower than other common aerogels.

To study the graphitization of CAs with different amounts of hydrochloric acid (0.1 M), Raman spectra are recorded, as exhibited in Figure 2. All of the CAs show similar spectra including $\mathrm{D}$ and $\mathrm{G}$ band at around 1340 and $1580 \mathrm{~cm}^{-1}$, respectively. Generally, the D band is assigned to the disorder or defect introduced during preparation, while the $G$ band originates from $E_{2 g}$ symmetry, which is associated with the degree of graphitization of carbon materials. The intensity ratio of $D$ band and $G$ band $\left(I_{D} / I_{G}\right)$ of each sample is at around 1, indicating that the as-prepared carbon aerogels are amorphous carbon with defects and graphitization in some areas. The defects and irregularities promotes the production of micropores [5], while the ordered graphitic structure can improve the electronic conductivity of CAs. [29]

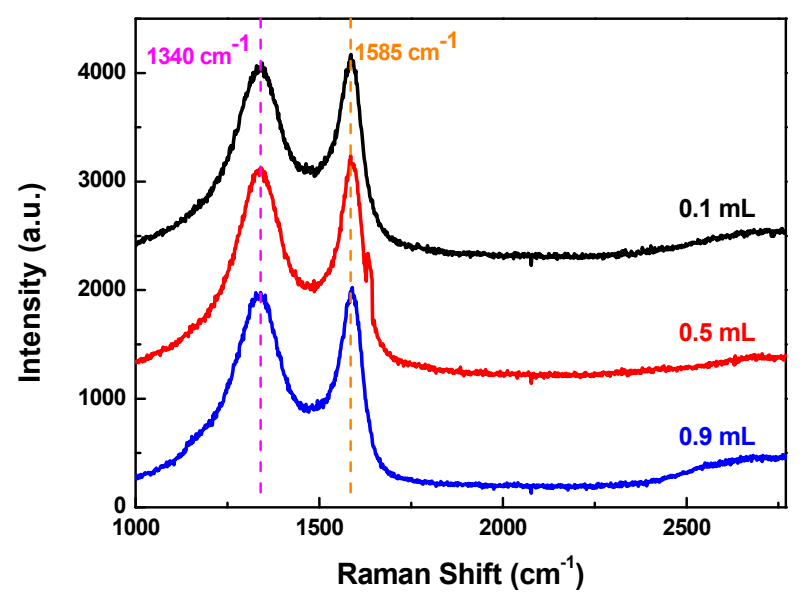

Figure 2. Raman spectrum of CAs prepared with different amounts of $\mathrm{HCl}$ solution $(0.1 \mathrm{M})$.

All the morphology of carbon aerogels prepared by different hydrochloric acid amounts are similar. Figure 3 shows the SEM of carbon aerogels prepared by adding 0.1 and $0.5 \mathrm{~mL}$ hydrochloric acid, respectively. The results show that the carbon aerogel has a typical 3D cocontinuous skeletons, which are formed by the connection of micron spherical carbon particles. Rich macropores with a large size are formed between the skeletons. With the increase of the amount of hydrochloric acid, the average size of carbon spheres decreases gradually from 8-9 to $4-5 \mu \mathrm{m}$, the uniformity is significantly improved, and the skeletons are gradually refined. When the amount of $0.1 \mathrm{M}$ hydrochloric acid exceeds $0.5 \mathrm{~mL}$, the size of carbon spheres tends to be stable with a distribution of $4-5 \mu \mathrm{m}$, but the uniformity of carbon spheres decreases and the surface roughness increases obviously, with the appearance of the ellipsoidal particles. These findings are in an agreement that the an appropriate amount of hydrochloric acid accelerates the reaction of this system, resulting in the rise in porosity with ungrown carbon spheres, but excess amount of hydrochloric acid will reduce the uniformity of carbon spheres.

Figure 4 shows the adsorption-desorption isotherms of carbon aerogels with different $\mathrm{HCl}$ solution amounts. According to the IUPAC classification, all samples exhibit the isotherm of type I without obvious hysteresis loop, which indicates that there exist only micropores in CAs, almost no mesopores. Additionally, the adsorption capacity increases rapidly in the low pressure region, indicating that there are abundant micropores in the samples [30]. Combined with SEM images, these pores are formed by the accumulation of carbon spheres. Figure $4 \mathrm{~b}$ shows the pore size distribution of the 
sample added $0.5 \mathrm{~mL}$ hydrochloric acid, which shows that there are abundant micropores in the sample, without mesopores. As shown in Figure 4c, the BET-specific surface area of carbon aerogels increases at first and then decreases with the increase of hydrochloric acid amount. When the amount of hydrochloric acid is $0.5 \mathrm{~mL}$, the specific surface area reaches the highest, which is $645.9 \mathrm{~m}^{2} \cdot \mathrm{g}^{-1}$. Excessive addition of hydrochloric acid will decrease specific surface area of carbon aerogels.
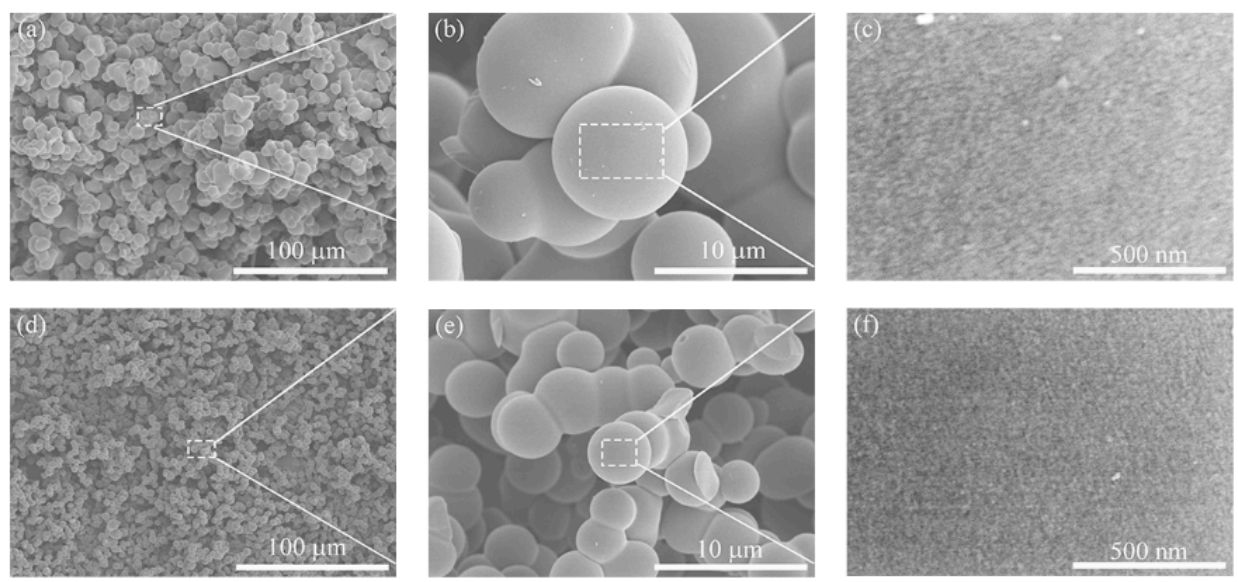

Figure 3. SEM images of carbon aerogels prepared with different amounts of $0.1 \mathrm{M} \mathrm{HCl}$ solution: $(\mathbf{a}-\mathbf{c}) 0.1 \mathrm{~mL} ;(\mathbf{d}-\mathbf{f}) 0.5 \mathrm{~mL}$.
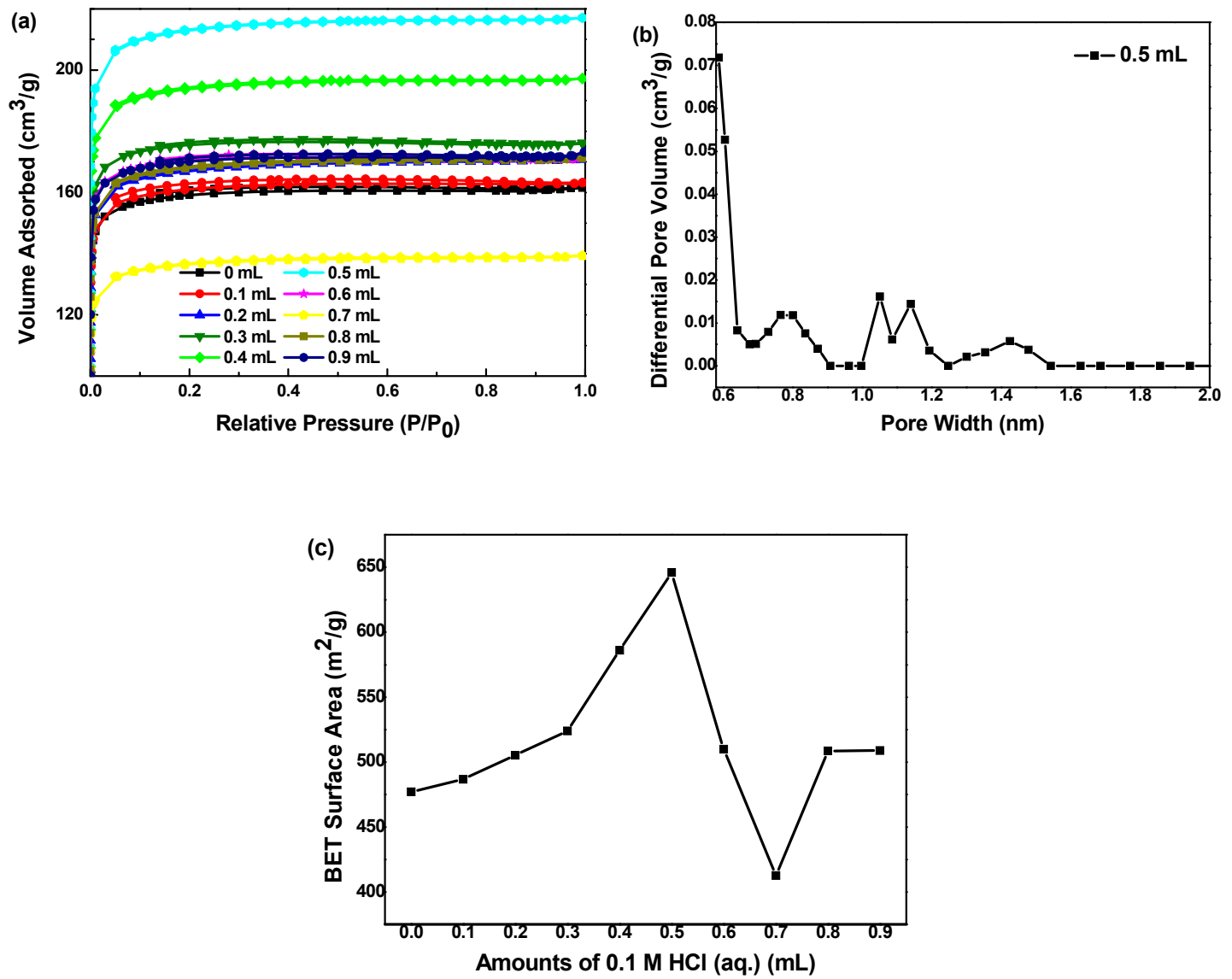

Figure 4. BET results of carbon aerogels prepared with different amounts of $0.1 \mathrm{M} \mathrm{HCl}$ solution: (a) $\mathrm{N}_{2}$ adsorption and desorption curves; (b) The pore diameter distribution curve calculated by BJH model of the sample prepared with $0.5 \mathrm{~mL} \mathrm{HCl}$ solution; (c) Relationship between BET-specific surface area and $\mathrm{HCl}$ solution amount. 
The TG/DTG of organic aerogel in $\mathrm{N}_{2}$ atmosphere is shown in Figure 5. With the increase of temperature, the weight loss of RF aerogel occurs continuously, which can be divided into five stages. At $50-140{ }^{\circ} \mathrm{C}$, the weight loss rate is $3.37 \%$, which is contributed by the volatilization of a little underdried solvent and adsorbed water in the pores. At $140-270{ }^{\circ} \mathrm{C}$, the weight loss rate is $3.31 \%$, which is attributed to the further cross-linking curing of phenolic resin and removal of end groups such as methylol $\left(-\mathrm{CH}_{2} \mathrm{OH}\right)$. The pyrolysis products of this stage are mainly water $\left(\mathrm{H}_{2} \mathrm{O}\right)$, methanol $\left(\mathrm{CH}_{3} \mathrm{OH}\right)$ and other small molecules, so the weight loss rate is low. At $270-450{ }^{\circ} \mathrm{C}$, the weight loss rate is $10.15 \%$, which is due to the thermal decomposition process of ortho-ortho and ortho-para methylene. At $450 \sim 850{ }^{\circ} \mathrm{C}$, the weight loss rate is $23.75 \%$, which is caused by the decomposition of para-para-methylene and dehydro-carbonization stage and the weight loss rate is high. At $850-900{ }^{\circ} \mathrm{C}$, the mass of sample is stable and almost no weight loss occurs. The total weight loss is about $40.6 \%$, which matches the proportion of non-carbon elements in phenolic resin, indicating that the carbonization reaction is complete.

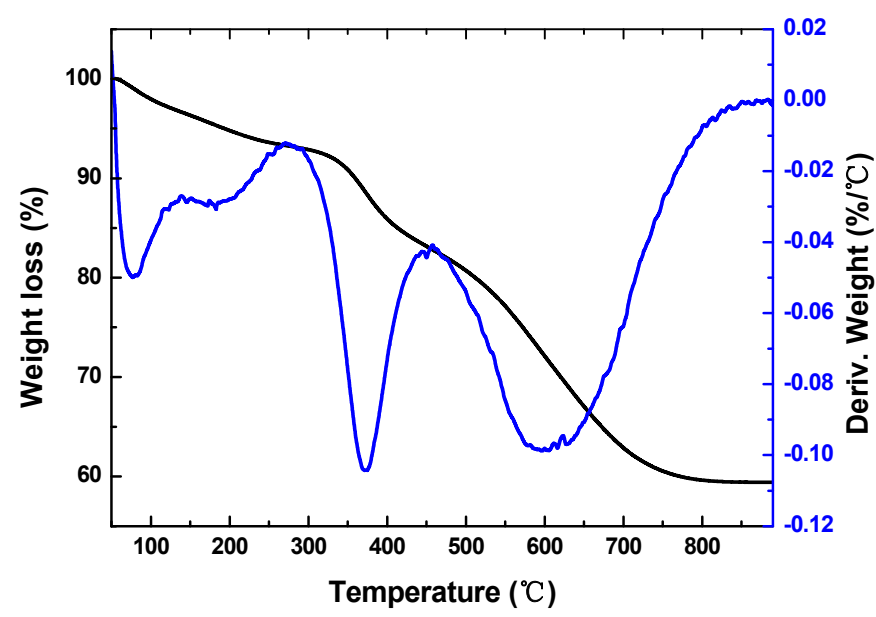

Figure 5. TG/DTG curves of resorcinol-formaldehyde (RF) organic aerogel.

According to the TG/DTG results of RF aerogel, the highest carbonization temperature is designed to be $900{ }^{\circ} \mathrm{C}$, which ensures that the organic aerogel can be completely carbonized into pure carbon materials, and the xerogel monolith will not shrink or break.

\subsection{Construction of Hierarchically Porous Carbon Aerogels}

In the process of preparing carbon aerogel with hydrochloric acid as catalyst, polyethylene glycol with molecular weight of 200, 400, 800 and 2000 are added as pore-forming agent to explore its effect on the pore structure of carbon aerogel, respectively. When PEG200 is used as pore-forming agent, the amount varies from 0.1 to $0.8 \mathrm{~g}$, the sample collapses on one side after gelation, and occurs obvious delamination phenomenon after drying. It can be seen that the uniformity is poor, and the particle size does not have obvious regularity. When PEG400 and PEG800 are used as pore-forming agents, the microstructure of carbon aerogels are similar to that of PEG200, which also have poor uniformity. When PEG2000 is used as pore forming agent, the gelation time of each sample is within $1 \mathrm{~h}$, and there is no shrinkage after drying. Surface morphologies of carbon aerogels prepared with varied PEG2000 amounts have been observed and recorded by SEM, as shown in Figure 6. With the increase of the addition of PEG2000, the morphologies vary a little, but the particle size of carbon spheres increases significantly. Further increase in PEG2000 will lead to poor uniformity or aggregation of carbon spheres. 

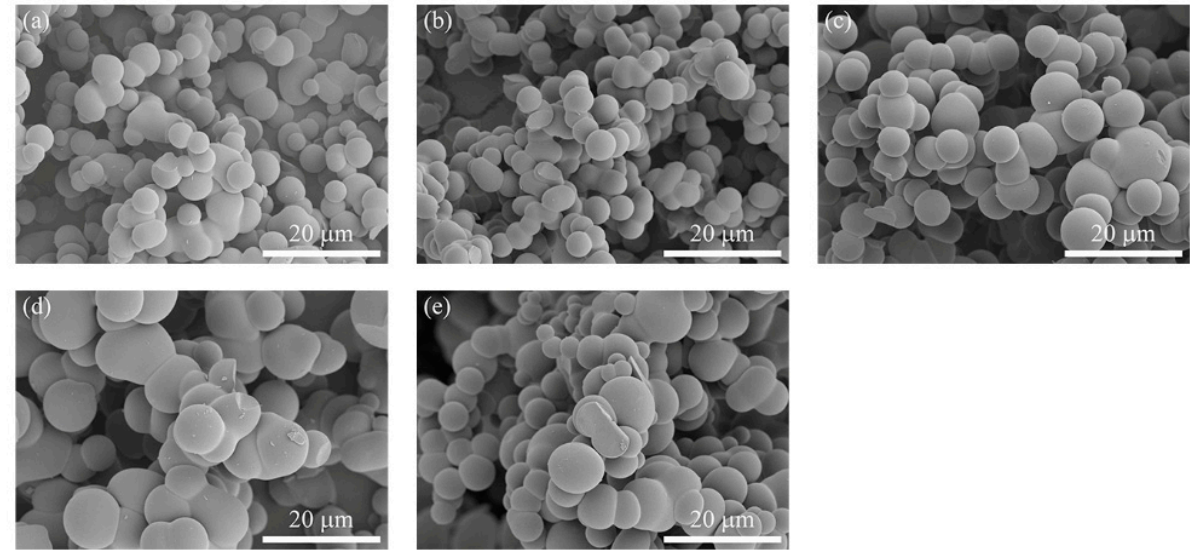

Figure 6. SEM images of carbon aerogels prepared with different PEG2000 amounts: (a) 0 g; (b) 0.2 g; (c) $0.4 \mathrm{~g}$; (d) $0.6 \mathrm{~g}$; (e) $0.8 \mathrm{~g}$.

The $\mathrm{N}_{2}$ adsorption-desorption isotherms of carbon aerogels prepared from different PEG2000 amounts are shown in Figure 7a. According to the IUPAC classification, all samples are found to exhibit an incomplete adsorption isothem of type IV with a elongated hysteresis loop of the H4 type. In addition, the adsorption capacity increases rapidly in the low pressure region, reaching the platform at $220,190,160,152$ and $140 \mathrm{~cm}^{3} \cdot \mathrm{g}^{-1}$, respectively, and keeps the platform stable when the pressure continues to increase. These results indicate that there are a large number of micropores or small mesopores in samples [31]. The inner surface area of samples is significantly higher than its outer surface area. The adsorption capacity is limited by the pore volume. The small pores corresponding to the turning point of the platform are completely filled with adsorbed gas.

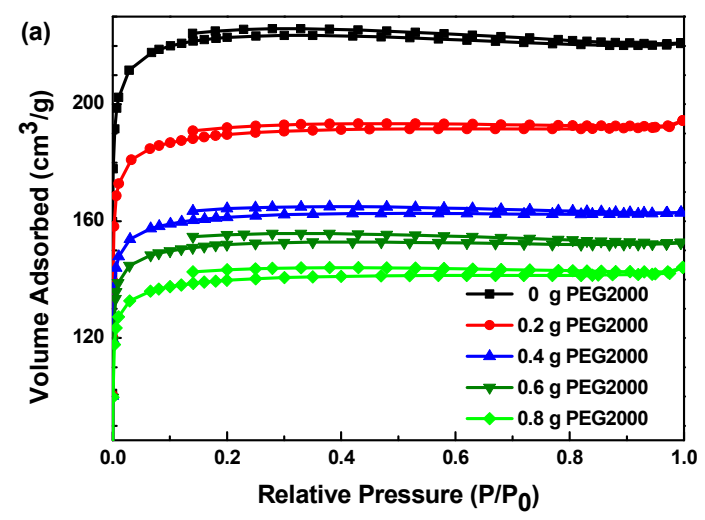

(a)

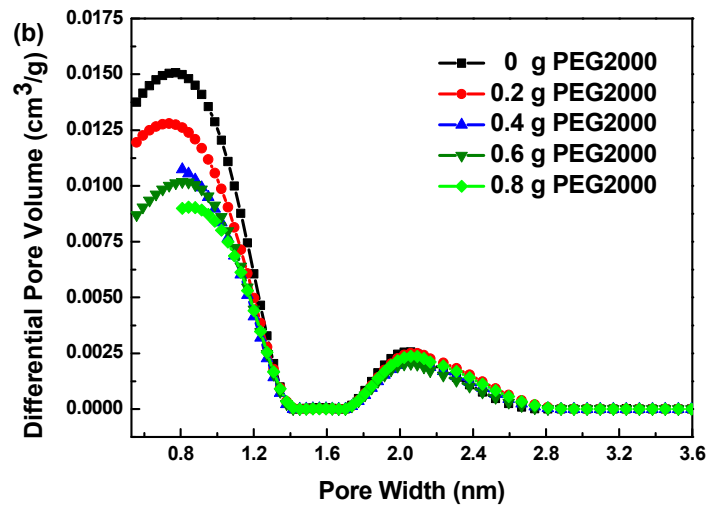

(b)

Figure 7. BET results of carbon aerogels prepared with different amounts of PEG2000: (a) $\mathrm{N}_{2}$ adsorption and desorption curves; (b) The pore diameter distribution curves calculated by BJH model.

The micropores size distribution was calculated by the $\mathrm{BJH}$ algorithm. From Figure $7 \mathrm{~b}$, it is seen that the addition of PEG2000 has little effect on the pore size distribution of carbon aerogels. The micropore sizes of carbon aerogels prepared with different amounts of PEG2000 are distributed in the range of around $0.6 \sim 1.0$ and $1.8 \sim 2.2 \mathrm{~nm}$. With the increase of PEG2000, the micropore volume decreases obviously, which also leads to the decrease of specific surface area, as shown in Table 1. It can be seen that the addition of PEG2000 increases the micropore size slightly with the appearance of small mesopores, while the total pore volume decreases. 
Table 1. Specific surface areas of carbon aerogels prepared with different amounts of PEG2000.

\begin{tabular}{cccccc}
\hline PEG2000/g & $\mathbf{0}$ & $\mathbf{0 . 2}$ & $\mathbf{0 . 4}$ & $\mathbf{0 . 6}$ & $\mathbf{0 . 8}$ \\
\hline BET-specific surface $\mathrm{area} / \mathrm{m}^{2} \cdot \mathrm{g}^{-1}$ & 665.1 & 568.8 & 482.9 & 455.1 & 419.2 \\
Pore volume $/ \mathrm{cm}^{3} \cdot \mathrm{g}^{-1}$ & 0.343 & 0.297 & 0.252 & 0.235 & 0.217 \\
Micropore surface area $/ \mathrm{m}^{2} \cdot \mathrm{g}^{-1}$ & 605.1 & 509.2 & 434.8 & 410.1 & 372.6 \\
Micropore volume $/ \mathrm{cm}^{3} \cdot \mathrm{g}^{-1}$ & 0.318 & 0.267 & 0.228 & 0.215 & 0.196 \\
\hline
\end{tabular}

The macropore size distribution was calculated by the mercury intrusion method. Figure 8 shows the macropore size distribution of carbon aerogels prepared with different amounts of PEG2000. When the addition of PEG2000 is $0,0.2,0.4,0.6$ and $0.8 \mathrm{~g}$, the median macropore size of the samples is distributed about $6.8,9.1,11.3,11.3$ and $12.8 \mu \mathrm{m}$, respectively. In particular, CA-13 exhibits super-large pore size distribution at about $21.3 \mu \mathrm{m}$. These results show that the addition of PEG2000 can effectively expand the original macropore size of carbon aerogels. When the amount of PEG2000 is less than $0.4 \mathrm{~g}$, the increase of its addition obviously enlarges the pore size; however, when the amount is more than $0.4 \mathrm{~g}$, the macropore size tends to be stable.
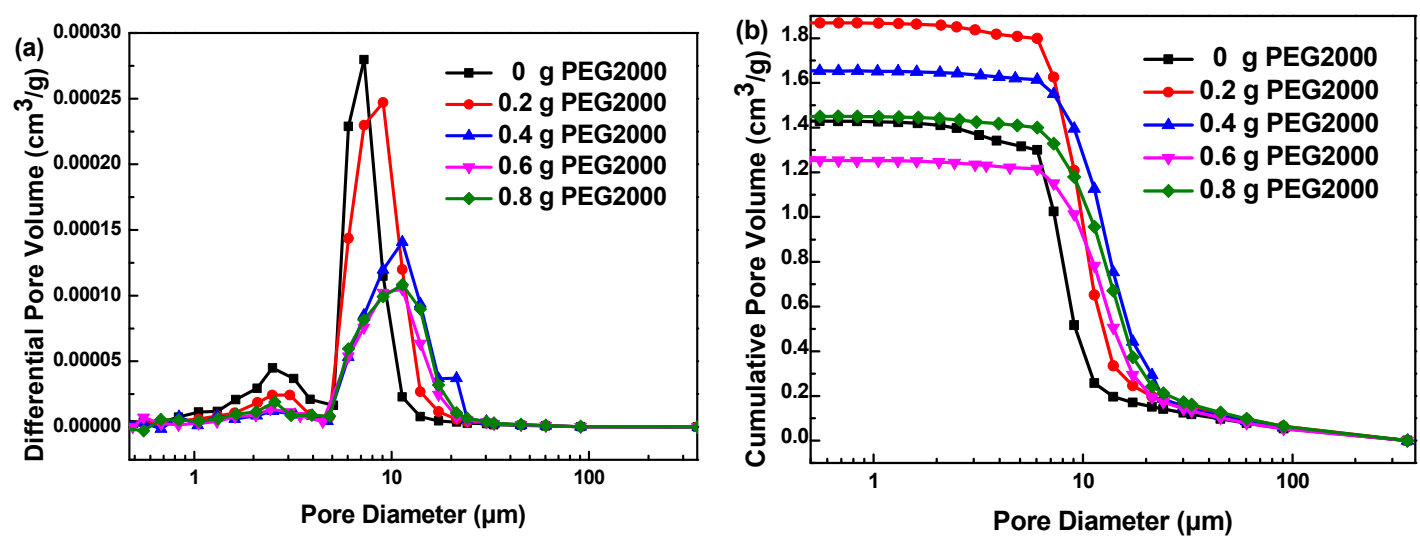

Figure 8. Macropore size distribution of carbon aerogels prepared with different amounts of PEG2000:

(a) differential pore volume curve; (b) cumulative pore volume curve.

Therefore, the addition of PEG2000 as a pore-forming agent in hydrochloric acid catalytic system can expand the pore size of carbon aerogels, the original micropore structure can be expanded to mesopores, and the macropore size also increases significantly, thus forming a kind of hierarchical pore structure (micropore-mesopore-macropore). In this process, the specific surface area decreases, but can still be higher than $400 \mathrm{~m}^{2} \cdot \mathrm{g}^{-1}$.

Polyethylene glycol (PEG) is a kind of polymer formed by the polymerization of ethylene oxide. It is a kind of water-soluble polymer with crystallinity and thermoplasticity. Its degree of polymerization can be changed in a large range. PEG is usually viscous liquid or wax like solid. The concentration of active end groups of this kind of resin is low, and it has certain water solubility due to the formation of hydrogen bond.

As is well known, the specific area is mainly produced by the porous structure. Meanwhile, the mesopores in CA matrix are mainly distributed between the particles, and the micropores mainly exist in the particles. However, the microstructural collapse and shrinkage of CA during carbonization lead to the disappear of mesopores and macropores. Therefore, the micropores is dominant in CAs [14]. In the system of hydrochloric acid, the added PEG2000 acts as a soft template and structure-directing agent in the reaction [25]. The condensation of resorcinol and formaldehyde small organic molecules around the PEG chain expands. Under suitable conditions, the structure with PEG2000 template and RF gel as support is formed. Due to the thermosetting of RF gel and the three-dimensional network structure strengthened by PEG2000, the volume shrinkage decreases. Additionally, RF gel also converts 
to carbon after carbonization, resulting in more abundant pores in aerogel and retaining the carbon skeletons formed after pyrolysis of organic gels.

\subsection{Transition Metal Oxides Loading of Hierarchically Porous Carbon Aerogels}

\subsubsection{Nano Manganese Oxide Loading of Carbon Aerogels}

X-ray photoelectron spectroscopy (XPS) is performed to investigate the chemical state of the elements in $\mathrm{MnO}_{\mathbf{x}} @ \mathrm{CA}$, as shown in Figure 9a,b. The wide survey spectrum confirms the existence of $\mathrm{Mn}, \mathrm{O}$ and C elements, and the Mn loading content is $2.89 \%$. From the high-resolution Mn 2p XPS spectrum of $\mathrm{MnO}_{\mathrm{x}} @ \mathrm{CA}$, it is obviously observed that the $\mathrm{Mn} 2 \mathrm{p}$ doublet is corresponding to $2 \mathrm{p}_{1 / 2}$ and $2 \mathrm{p}_{3 / 2}$ splitting peak. According to the flitting results, the $\mathrm{Mn} 2 \mathrm{p}_{3 / 2}$ spectra can be dissolved into two peaks at 643.0 and $641.5 \mathrm{eV}$, respectively. This demonstrates two different kinds of chemical states for $\mathrm{Mn}$ in $\mathrm{MnO}_{\mathrm{x}} @ \mathrm{CA}$. The main peak (centered at about $643.0 \mathrm{eV}$ ) is ascribed to $\mathrm{Mn}^{4+}$, while the peaks at binding energies of $641.5 \mathrm{eV}$ may be attributed to $\mathrm{Mn}^{3+}$. In addition, two corresponding peaks at 654.5 and $653.1 \mathrm{eV}$ are also observed, which are assigned to $\mathrm{Mn} 2 \mathrm{p}_{1 / 2}$ spectra of $\mathrm{Mn}^{4+}$ and $\mathrm{Mn}^{3+}$. Moreover, the $\mathrm{Mn} 2 \mathrm{p}_{1 / 2}$ and $2 \mathrm{p}_{3 / 2}$ are located at 654.3 and $642.6 \mathrm{eV}$, respectively, and the splitting energy level $\left(\Delta E_{\mathrm{b}}\right)$ is $11.7 \mathrm{eV}$, which is consistent with that previously reported [32]. The intensity and area of the peak clearly demonstrate that $\mathrm{MnO}_{\mathrm{x}}$ is $\mathrm{MnO}_{2}$ with a small amount of $\mathrm{Mn}_{2} \mathrm{O}_{3}$.
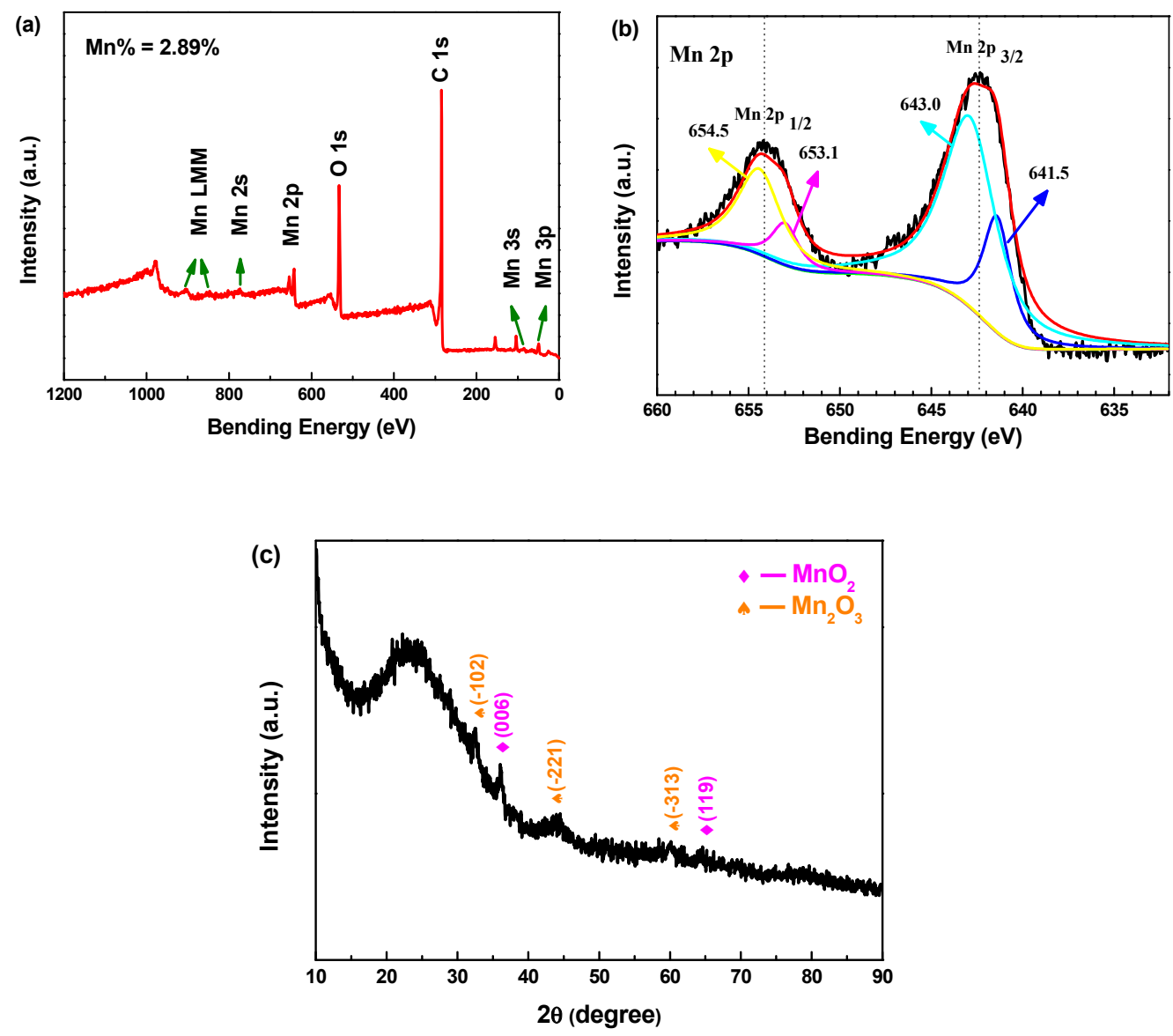

Figure 9. (a) Wide survey XPS spectrum, (b) high-resolution Mn 2p XPS spectrum; and (c) XRD spectra of $\mathrm{MnO}_{2} / \mathrm{Mn}_{2} \mathrm{O}_{3} @ \mathrm{CA}$ composite material.

The phase composition of $\mathrm{MnO}_{2} / \mathrm{Mn}_{2} \mathrm{O}_{3} @ \mathrm{CA}$ is evaluated by XRD analysis. As shown in Figure 9c, there has been weak characteristic peak of manganese oxide, which may be mainly covered by carbon substrate due to the small load. However, it can still be distinguished into two different phases. 
Two diffraction peaks at 36.8 and $65.7^{\circ}$ correspond to (006) and (119) planes of MnO. Three peaks appearing at $33.2,43.3$ and $60.5^{\circ}$ correspond to $(-102),(-221)$ and $(-313)$ panes of $\mathrm{Mn}_{2} \mathrm{O}_{3}$. It can be confirmed that the as-prepared product is with no other impurities.

To further investigate the morphology and microstructure of $\mathrm{MnO}_{2} / \mathrm{Mn}_{2} \mathrm{O}_{3} @ \mathrm{CA}$, scanning electron microscopy (SEM) is carried out. As shown in Figure 10, the carbon spheres on the carbon aerogel skeletons are etched to form a large number of pores, shaping into a nano-flower structure, which provides more potential active sites and accommodation space for loading manganese oxide nanoparticles. Mn and $\mathrm{O}$ are uniformly distributed on the surface and inside the pores of carbon spheres, which can be estimated by EDS analysis, but the loading of Mn element is not high. Combined with the results of XPS and XRD analysis, the uniform loading of $\mathrm{MnO}_{2} / \mathrm{Mn}_{2} \mathrm{O}_{3}$ nanoparticles in hierarchically porous carbon aerogel is successfully achieved by liquid phase synthesis, and $\mathrm{MnO}_{2} / \mathrm{Mn}_{2} \mathrm{O}_{3} @ \mathrm{CA}$ has uniform and controllable morphology.
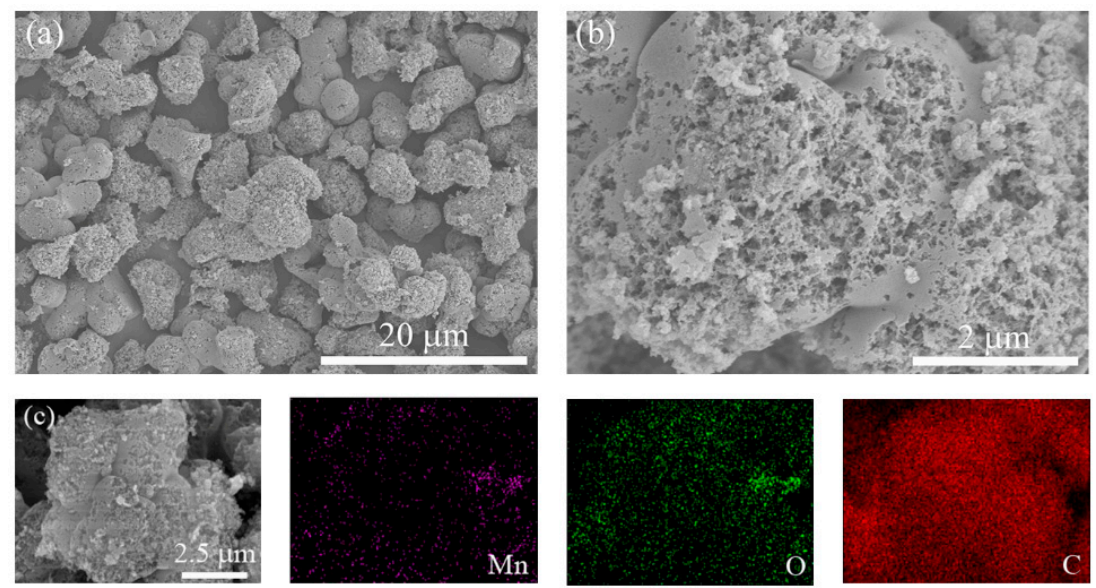

Figure 10. (a,b) SEM images; (c) EDS results of $\mathrm{MnO}_{2} / \mathrm{Mn}_{2} \mathrm{O}_{3} @ \mathrm{CA}$ composite material.

Nitrogen adsorption-desorption isotherm of $\mathrm{MnO}_{2} / \mathrm{Mn}_{2} \mathrm{O}_{3} @ C A$ sample is shown in Figure 11. Difference from the uncomposite carbon aerogel, the curve of loaded composite belongs to the typical type IV isotherm according to the IUPAC classification. Such isotherm shows an obvious hysteresis loop at the $P / P_{0}$ between 0.10 and 0.80 , owing to the presence of a large amount of mesoporous in the sample, which is consistent with the morphology of SEM. The BET-specific surface area of $\mathrm{MnO}_{2} / \mathrm{Mn}_{2} \mathrm{O}_{3} @ \mathrm{CA}$ is as high as $505.7 \mathrm{~m}^{2} \cdot \mathrm{g}^{-1}$.
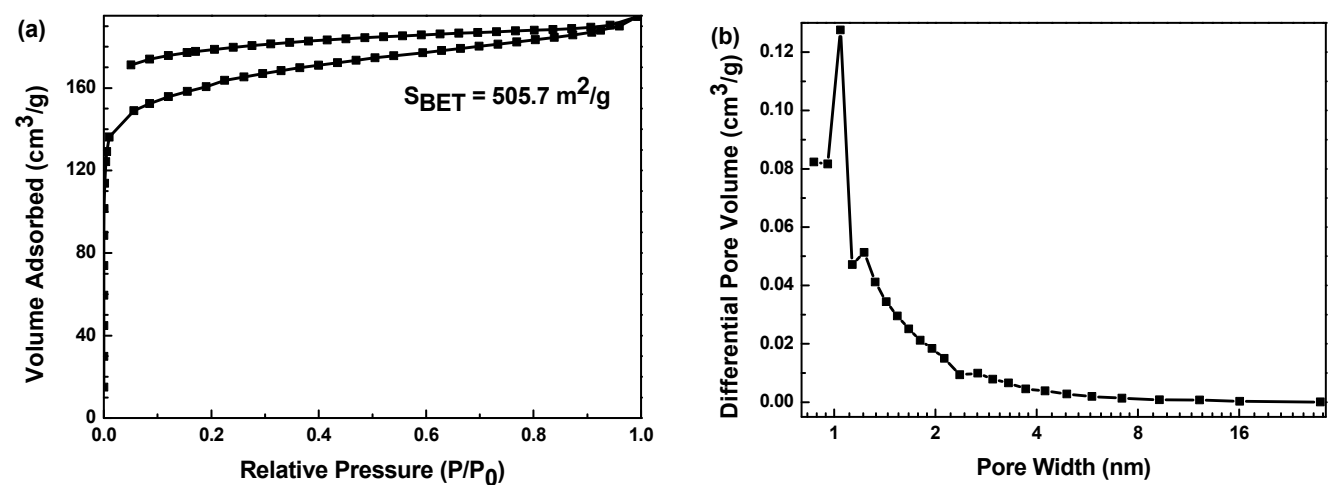

Figure 11. (a) $\mathrm{N}_{2}$ adsorption-desorption isotherm; (b) pore diameter distribution of $\mathrm{MnO}_{2} / \mathrm{Mn}_{2} \mathrm{O}_{3} @ \mathrm{CA}$ composite material.

\subsubsection{Nano Nickel Oxide Loading of Carbon Aerogels}

XPS is also performed to investigate the chemical state of the elements in $\mathrm{NiO}_{\mathrm{x}} @ \mathrm{CA}$, as shown in Figure 12a,b. It can be observed from Figure 12a that the survey spectrum reveals the presence 
of the elements nickel and oxygen in the structure of $\mathrm{CA}$, and the $\mathrm{Ni}$ loading content is $1.37 \%$. The high-resolution XPS spectra of $\mathrm{NiO}_{x} @ \mathrm{CA}$ corresponding to the binding energies for the $\mathrm{Ni} 2 \mathrm{p}$ is analyzed in Figure 12b. Typical prominent doublet peaks of the sample are located at approximately 872.58 and $853.78 \mathrm{eV}$, with one satellite peak at 880.03 and $861.03 \mathrm{eV}$, corresponding to the $\mathrm{Ni} 2 \mathrm{p}_{1 / 2}$ and $\mathrm{Ni} 2 \mathrm{p}_{3 / 2}$ main level binding energies of $\mathrm{Ni}$, respectively. Additionally, the $\mathrm{Ni} 2 \mathrm{p}$ level splitting energy $\left(\Delta E_{\mathrm{b}}\right)$ is $18.8 \mathrm{eV}$, which is consistent with that previously reported [30]. The Ni 2p peaks in $\mathrm{NiO}_{\mathrm{x}} @ \mathrm{CA}$ are observed at 873.43 and $855.48 \mathrm{eV}$, which may be attributed to the presence of $\mathrm{Ni}^{2+}$, and other two peaks may correspond to $\mathrm{Ni}^{0}(872.13$ and $853.68 \mathrm{eV})$.
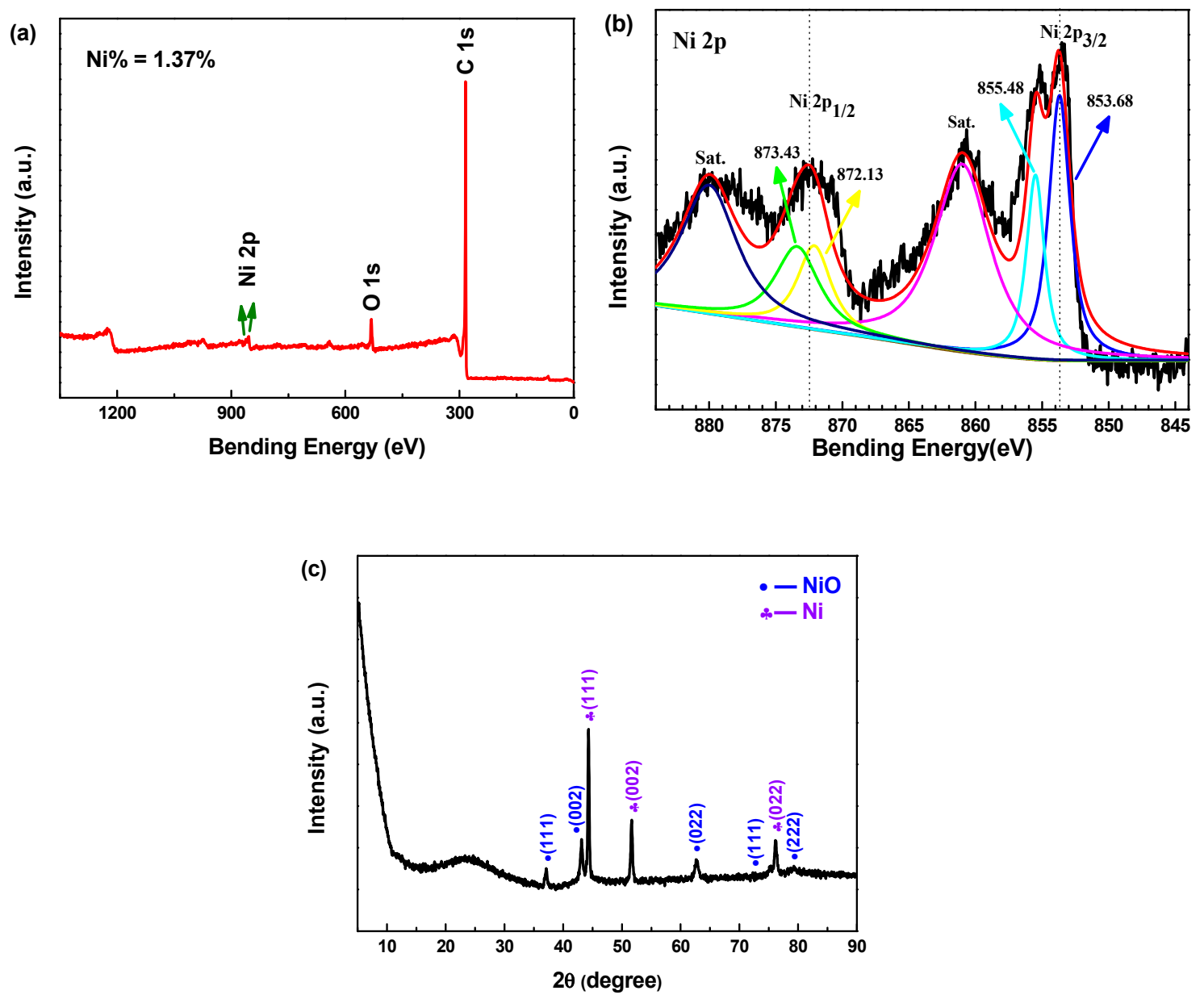

Figure 12. (a) Wide survey XPS spectrum; (b) high-resolution Ni 2p XPS spectrum; (c) XRD spectra of $\mathrm{Ni} / \mathrm{NiO} @ \mathrm{CA}$ composite material.

The XRD pattern of the obtained composite is shown in Figure 12c. The peaks at $37.12^{\circ}, 43.12^{\circ}$, $62.71^{\circ}, 75.35^{\circ}$ and $79.29^{\circ}$ can be assigned to (111), (002), (022), (311) and (222) of cubic NiO, respectively, and the peaks at $44.32,51.67$ and $76.13^{\circ}$ can be assigned to (111), (002) and (022) of Ni with the same cubic structure as $\mathrm{NiO}$. According to the Bragg equation, the lattice constants of cubic $\mathrm{NiO}$ and cubic $\mathrm{Ni}$ are 4.180 and $3.540 \AA$, respectively, which are consistent with that previously reported [33,34]. All of the sharp diffraction and defined peaks indicate that the sample is highly crystallized, and no other obvious impurity peaks are detected.

The morphology and structure of the obtained $\mathrm{Ni} / \mathrm{NiO} @ \mathrm{CA}$ are characterized by scanning electron microscopy (SEM). Figure 13 shows that the carbon spheres are etched to form a large number of pores after loading. Unlike the previous Mn loading, most of these pores are mesopores that are smaller than $50 \mathrm{~nm}$, but they can also provide many potential active sites and accommodation space for loading nickel and nickel oxide nanoparticles. After loading, the skeletons of Ni/NiO@CA still maintain 
a complete carbon spherical structure, with no obvious structural damage or collapse. In addition, the elemental mapping images of $\mathrm{Ni}$ and $\mathrm{O}$ (Figure 13) verify the homogeneous distribution of nickel and nickel oxide on the surface and inside the pores of carbon aerogel, but the loading of Ni element is not high. Combined with the results of XPS and XRD analysis, the uniform loading of $\mathrm{Ni} / \mathrm{NiO}$ nanoparticles in hierarchically porous carbon aerogel is successfully achieved by liquid phase synthesis, and the Ni/NiO@CA has uniform and controllable morphology.
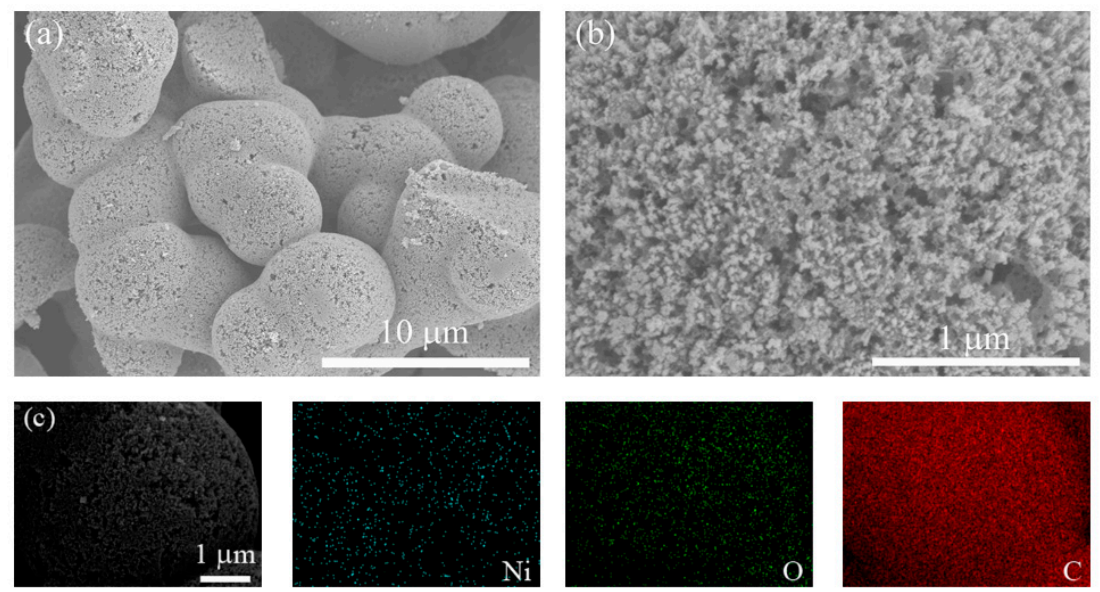

Figure 13. (a,b) SEM images; (c) EDS results of Ni/NiO@CA composite material.

To further investigate the porosity of Ni/NiO@CA composite material, the nitrogen adsorption-desorption isotherm measurement was also employed, and the isotherm is shown in Figure 14a. The curve exhibits a mixture of type I and IV following the IUPAC classification. The pore size distribution curve which is depicted in Figure 14b also confirms the micro-mesopore structure in the composites.
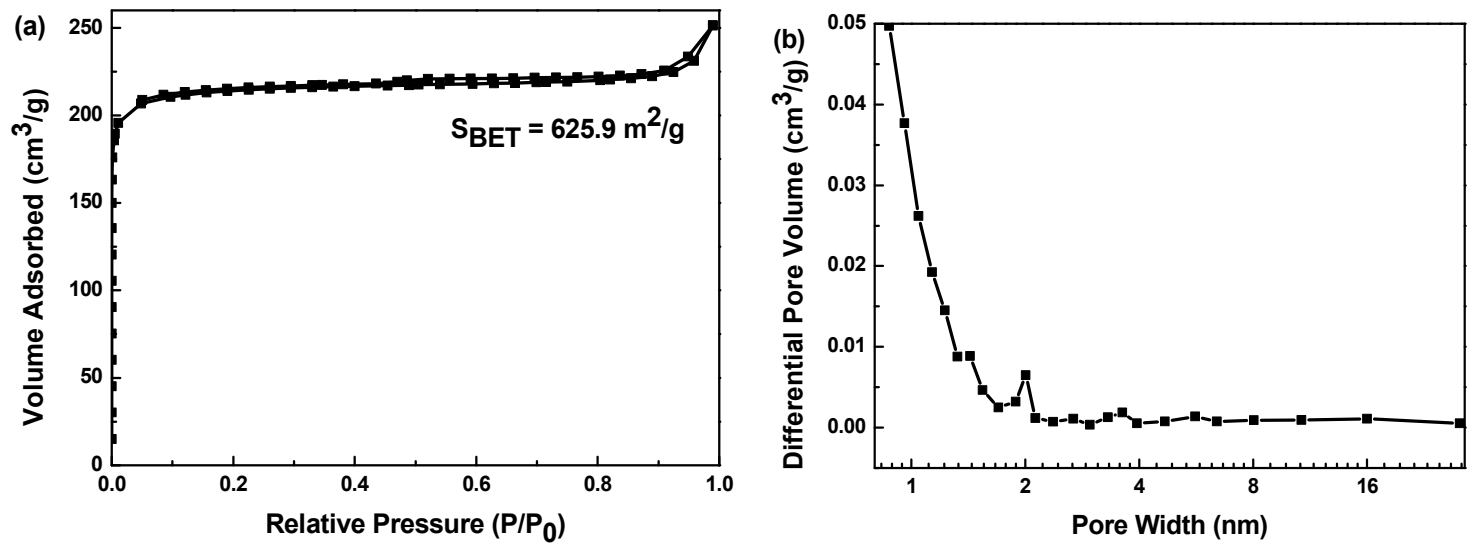

Figure 14. (a) $\mathrm{N}_{2}$ adsorption-desorption isotherm; (b) pore diameter distribution of $\mathrm{Ni} / \mathrm{NiO} @ \mathrm{CA}$ composite material.

As a kind of chemical activation method, liquid etching has been widely used in the activation of carbon materials. In this transition metal oxides loading process, the chemical reagents (ammonia solution, $\mathrm{NH}_{4} \mathrm{HCO}_{3}$ ) react with carbon aerogels, which results in the liquid etching of carbon spheres. The carbon in the carbon spheres will be consumed and developed to be the pores, and the reactive gas $\left(\mathrm{CO}_{2}, \mathrm{NH}_{3}\right)$ will expand the micropores to form large mesopores. It indicates that liquid etching is an effective approach to construct mesopore structure. 


\section{Experimental Section}

\subsection{Materials}

Resorcinol ( $R$, CAS 108-46-3, Aladdin, Shanghai, China, 99\%), formaldehyde solution (F, CAS 50-00-0, Sinopharm Chemical Reagent Co., Ltd., Shanghai, China, 37\% 40\%), hydrochloric acid (HCl, CAS 7647-01-0, Sinopharm Chemical Reagent Co., Ltd., Shanghai, China, 36 38\%), ethanol (CAS 64-17-5, Sinopharm Chemical Reagent Co., Ltd., Shanghai, China, AR), polyethylene glycol (PEG, CAS 25322-68-3, Aladdin, Shanghai, China, AR), nickel nitrate hexahydrate $\left(\mathrm{Ni}\left(\mathrm{NO}_{3}\right)_{2} \cdot 6 \mathrm{H}_{2} \mathrm{O}\right.$, CAS 13478-00-7, Aladdin, Shanghai, China, AR), manganese chloride ( $\mathrm{MnCl}_{2}$, CAS 7773-01-5, Aladdin, Shanghai, China, 99\%) were used without further purification in this experimental.

\subsection{Preparation and Loading of Hierarchically Porous Carbon Aerogels}

\subsubsection{Preparation of Hierarchically Porous Carbon Aerogels}

Samples were prepared with the starting compositions listed in Table 2 . Firstly, catalyst $(0.1 \mathrm{~mol} / \mathrm{L}$ $\mathrm{HCl}$ ) and polyethylene glycol (PEG, $M_{w}=200,400,800$ and 2000) were dissolved in deionized water. Then, $2.75 \mathrm{~g}$ resorcinol $(\mathrm{R})$ and $3.61 \mathrm{~mL}$ formaldehyde solution $(\mathrm{F})$ were added to the solution. After stirring for $1 \mathrm{~h}$, the RF solution was sealed and cured in $60^{\circ} \mathrm{C}$ for $24 \mathrm{~h}$. The resulting RF wet gels with dark red in color were immersed in ethanol for $24 \mathrm{~h}$ and then dried in $45^{\circ} \mathrm{C}$ for 2 days to prepare RF aerogels. The organic aerogels were carbonized in argon at $900{ }^{\circ} \mathrm{C}$ for $1 \mathrm{~h}$ at a heating rate of $1^{\circ} \mathrm{C} \cdot \mathrm{min}^{-1}$. Finally, the carbon aerogels (CAs) were obtained.

Table 2. Starting compositions of samples.

\begin{tabular}{cccccc}
\hline Sample & HCl/mL & PEG/g & Water/mL & R/g & F/mL \\
\hline CA-1 & 0 & 0 & 7.45 & 2.75 & 3.61 \\
CA-2 & 0.1 & 0 & 7.45 & 2.75 & 3.61 \\
CA-3 & 0.2 & 0 & 7.35 & 2.75 & 3.61 \\
CA-4 & 0.3 & 0 & 7.25 & 2.75 & 3.61 \\
CA-5 & 0.4 & 0 & 7.15 & 2.75 & 3.61 \\
CA-6 & 0.5 & 0 & 7.05 & 2.75 & 3.61 \\
CA-7 & 0.6 & 0 & 6.95 & 2.75 & 3.61 \\
CA-8 & 0.7 & 0 & 6.85 & 2.75 & 3.61 \\
CA-9 & 0.8 & 0 & 6.75 & 2.75 & 3.61 \\
CA-10 & 0.9 & 0 & 6.65 & 2.75 & 3.61 \\
CA-11 & 1.0 & 0 & 6.55 & 2.75 & 3.61 \\
CA-12 & 0.5 & 0.2 & 7.55 & 2.75 & 3.61 \\
CA-13 & 0.5 & 0.4 & 7.55 & 2.75 & 3.61 \\
CA-14 & 0.5 & 0.6 & 7.55 & 2.75 & 3.61 \\
CA-15 & 0.5 & 0.8 & 7.55 & 2.75 & 3.61 \\
\hline
\end{tabular}

\subsubsection{Loading of Hierarchically Porous Carbon Aerogels}

Synthesis of $\mathrm{MnO}_{2} / \mathrm{Mn}_{2} \mathrm{O}_{3} @ C A$. $0.25 \mathrm{~g}$ carbon aerogel was added to $10 \mathrm{~mL} 3 \mathrm{M}$ ammonia solution, stirred under $90{ }^{\circ} \mathrm{C}$ oil bath for $20 \mathrm{~h}$. Then, the precipitation was added to $10 \mathrm{~mL} 0.05 \mathrm{M} \mathrm{MnCl}_{2}$, stirred under $75^{\circ} \mathrm{C}$ oil bath for $24 \mathrm{~h}$, and dried in $60^{\circ} \mathrm{C}$. After that, the sample was heat treated in argon at $500{ }^{\circ} \mathrm{C}$ for $3 \mathrm{~h}$ at a heating rate of $1{ }^{\circ} \mathrm{C} / \mathrm{min}$. Finally, the carbon aerogel loaded with $\mathrm{MnO}_{2} / \mathrm{Mn}_{2} \mathrm{O}_{3}$ nanoparticles was obtained.

Synthesis of Ni/NiO@CA. $0.25 \mathrm{~g}$ carbon aerogel and $145.5 \mathrm{mg} \mathrm{Ni}\left(\mathrm{NO}_{3}\right)_{2} \cdot 6 \mathrm{H}_{2} \mathrm{O}$ powder were added to $10 \mathrm{~mL}$ deionized water and stirred at room temperature for $30 \mathrm{~min}$, then the solution was added $5 \mathrm{~mL} 0.5 \mathrm{M} \mathrm{NH}_{4} \mathrm{HCO}_{3}$ and stirred for $24 \mathrm{~h}$. After dried in $60{ }^{\circ} \mathrm{C}$, the sample was heat-treated in argon at $600{ }^{\circ} \mathrm{C}$ for $2 \mathrm{~h}$ at a heating rate of $1^{\circ} \mathrm{C} \cdot \mathrm{min}^{-1}$. Finally, the carbon aerogel loaded with $\mathrm{Ni} / \mathrm{NiO}$ nanoparticles was obtained. 
The production yield $(\gamma)$ of transition metal oxides in carbon aerogel calculated by the formula: $\gamma=$ molar mass of the Mn (or Ni) loaded/ molar mass of the Mn (or Ni) in the raw material. After calculation, the $\gamma$ of $\mathrm{MnO}_{2} / \mathrm{Mn}_{2} \mathrm{O}_{3}$ in CAs is about $80.64 \%$, and the $\gamma$ of $\mathrm{Ni} / \mathrm{NiO}$ in CAs is about $57.88 \%$.

\subsection{Characterization}

The Raman spectra were recorded from 1000 to $2800 \mathrm{~cm}^{-1}$ using a micro Raman apparatus (LabRAM HR Evolution, Horiba Jobin Yvon, Paris, France). The microstructures of the synthesized materials were observed by the scanning electron microscope (SEM, SU-8010, Hitachi, Tokyo, Japan) coupled with energy-dispersive X-ray spectroscopy (EDS). The specific surface area was determined by nitrogen adsorption (BET-method, ASAP2460, Micromeritics Instruments Corporation, Norcross, GA, USA), and the macropore size distribution was determined by mercury injection apparatus (AutoPore IV 9510, Micromeritics Instruments Corporation, Norcross, GA, USA). Phase identification of prepared samples was done by X-ray diffractometer (XRD, D8 ADVANCE, Bruker AXS, Karlsruhe, Germany) and X-ray photoelectron spectrometer (XPS, ESCALAB 250Xl, ThermoFisher Scientific, Waltham, MA, USA).

\section{Conclusions}

Hierarchically porous carbon aerogels and their composites were prepared by process optimization, pore structure regulation and nano-loading. When the amount of $\mathrm{HCl}$ solution $(0.1 \mathrm{M})$ is $0.5 \mathrm{~mL}$, and the amount of PEG2000 used as pore-formation agent is $0.4 \mathrm{~g}$, micro-meso-macroporous CAs with a BET surface area of $482.9 \mathrm{~m}^{2} \cdot \mathrm{g}^{-1}$ and a macropore size of $11.3 \mu \mathrm{m}$ can be achieved. With hierarchically porous carbon aerogels as substrates, the transition metal oxide nanoparticles were loaded to prepare $\mathrm{MnO}_{2} / \mathrm{Mn}_{2} \mathrm{O}_{3} @ \mathrm{CA}$ and $\mathrm{Ni} / \mathrm{NiO} @ \mathrm{CA}$ composite materials by means of etching and loading combined with heat treatment. After loading, the framework of carbon aerogels is etched into mesoporous structure with a specific surface area as high as $625.9 \mathrm{~m}^{2} \cdot \mathrm{g}^{-1}$ and the transition metal oxide nanoparticles distribute uniformly in CAs. The construction of hierarchical porous structure, the loading of transition metal oxide nanoparticles and atmospheric drying technology will reduce the preparation cost and widen the application range of carbon aerogels.

Author Contributions: Conceptualization, J.W., H.L. and X.G.; Data curation, J.W.; Formal analysis, J.W.; Investigation, J.W., X.R. and J.Q.; Methodology, J.W. and H.L.; Project administration, X.G.; Resources, X.G. and H.Y.; Writing - original draft, J.W.; Writing_review \& editing, J.W. and X.G. All authors have read and agreed to the published version of the manuscript.

Funding: This research was funded by the National Natural Science Foundation of China, grant number 21875217 and 51372225; Industry-University-Research Collaboration Project of Jiangsu Province, grant number FZ20180405 and the High Science \& Technique Brainstorm Project of Zhejiang Province of China, grant number No. $2017 C 01002$.

Acknowledgments: This work is supported by the National Natural Science Foundation of China (21875217 and 51372225) and Industry-University-Research Collaboration Project of Jiangsu Province (FZ20180405) and the High Science \& Technique Brainstorm Project of Zhejiang Province of China (No. 2017C01002). The authors acknowledge the help for funding acquisition of Ronghua Ding, Yun Zhang and Wei Lei (Pan Asia Microvent Tech (Jiangsu) Coporation \& Zhejiang University Micro-nano-porous Materials Joint Research Development Center).

Conflicts of Interest: The authors declare no conflict of interest.

\section{References}

1. Siyasukh, A.; Maneeprom, P.; Larpkiattaworn, S.; Tonanon, N.; Tanthapanichakoon, W.; Tamon, H.; Charinpanitkul, T. Preparation of a carbon monolith with hierarchical porous structure by ultrasonic irradiation followed by carbonization, physical and chemical activation. Carbon 2008, 46, 1309-1315. [CrossRef]

2. Zhang, Z.; Dong, Z.; Wang, X.; Dai, Y.; Cao, X.; Wang, Y.; Hua, R.; Feng, H.; Chen, J.; Liu, Y.; et al. Synthesis of ultralight phosphorylated carbon aerogel for efficient removal of U(VI): Batch and fixed-bed column studies. Chem. Eng. J. 2019, 370, 1376-1387. [CrossRef] 
3. Yang, Z.; Qiao, W.-M.; Liang, X.-Y. Modelling and optimization of the pore structure of carbon aerogels using an artificial neural network. New Carbon Mater. 2017, 32, 77-85. [CrossRef]

4. Lee, Y.J.; Jung, J.C.; Park, S.; Seo, J.G.; Baeck, S.-H.; Yoon, J.R.; Yi, J.; Song, I.K. Effect of preparation method on electrochemical property of Mn-doped carbon aerogel for supercapacitor. Curr. Appl. Phys. 2011, 11, 1-5. [CrossRef]

5. Zhang, C.; Wang, X.; Wang, H.; Wu, X.; Shen, J. A positive-negative alternate adsorption effect for capacitive deionization in nano-porous carbon aerogel electrodes to enhance desalination capacity. Desalination 2019, 458, 45-53. [CrossRef]

6. Ahamad, T.; Naushad, M.; Ruksana; Alhabarah, A.N.; Alshehri, S.M. N/S doped highly porous magnetic carbon aerogel derived from sugarcane bagasse cellulose for the removal of bisphenol A. Int. J. Biol. Macromol. 2019, 132, 1031-1038. [CrossRef]

7. Abolhasani, S.; Ahmadpour, A.; Rohani Bastami, T.; Yaqubzadeh, A. Facile synthesis of mesoporous carbon aerogel for the removal of ibuprofen from aqueous solution by central composite experimental design (CCD). J. Mol. Liq. 2019, 281, 261-268. [CrossRef]

8. Feng, J.; Feng, J.; Zhang, C. Thermal conductivity of low density carbon aerogels. J. Porous Mater. 2011, 19, 551-556. [CrossRef]

9. Kim, S.J.; Hwang, S.W.; Hyun, S.H. Preparation of carbon aerogel electrodes for supercapacitor and their electrochemical characteristics. J. Mater. Sci. 2005, 40, 725-731. [CrossRef]

10. Fang, B.; Wei, Y.Z.; Maruyama, K.; Kumagai, M. High capacity supercapacitors based on modified activated carbon aerogel. J. Appl. Electrochem. 2005, 35, 229-233. [CrossRef]

11. Schmitt, C.; Pröbstle, H.; Fricke, J. Carbon cloth-reinforced and activated aerogel films for supercapacitors. J. Non-Cryst. Solids 2001, 285, 277-282. [CrossRef]

12. Chen, S.; Zhang, X.; Shen, P. Macroporous conducting matrix: Fabrication and application as electrocatalyst support. Electrochem. Commun. 2006, 8, 713-719. [CrossRef]

13. Zhao, H.; Shen, X.; Chen, Y.; Zhang, S.N.; Gao, P.; Zhen, X.; Li, X.H.; Zhao, G. A COOH-terminated nitrogen-doped carbon aerogel as a bulk electrode for completely selective two-electron oxygen reduction to $\mathrm{H}_{2} \mathrm{O}_{2}$. Chem. Commun. 2019, 55, 6173-6176. [CrossRef] [PubMed]

14. Yan, Y.; Shi, M.; Zou, Y.; Wei, Y.; Chen, L.; Fan, C.; Yang, R.; Xu, Y. Tunable hierarchical porous carbon aerogel/graphene composites cathode matrix for Li-S batteries. J. Alloy. Compd. 2019, 791, 952-961. [CrossRef]

15. Xu, Y.; Wang, S.; Yan, M.; Zhang, L.; Liu, Z. Synthesis, characterization and electrochemical properties of S-doped carbon aerogels. Solid State Ion. 2018, 321, 91-97. [CrossRef]

16. Wang, W.-K.; Tang, B.; Liu, J.; Shi, H.; Xu, Q.; Zhao, G. Self-supported microbial carbon aerogel bioelectrocatalytic anode promoting extracellular electron transfer for efficient hydrogen evolution. Electrochim. Acta 2019, 303, 268-274. [CrossRef]

17. Li, X.; Feng, J.; Jiang, Y.; Li, L.; Feng, J. Anti-oxidation performance of carbon aerogel composites with SiCO ceramic inner coating. Ceram. Int. 2019, 45, 9704-9711. [CrossRef]

18. Linneen, N.; Delnick, F.; Islam, S.Z.; Deshmane, V.G.; Bhave, R. Application of the macrohomogeneous line model for the characterization of carbon aerogel electrodes in capacitive deionization. Electrochim. Acta 2019, 301, 1-7. [CrossRef]

19. Liu, X.; Liu, H.; Mi, M.; Kong, W.; Ge, Y.; Hu, J. Nitrogen-doped hierarchical porous carbon aerogel for high-performance capacitive deionization. Sep. Purif. Technol. 2019, 224, 44-50. [CrossRef]

20. Li, F.; Xie, L.; Sun, G.; Kong, Q.; Su, F.; Cao, Y.; Wei, J.; Ahmad, A.; Guo, X.; Chen, C.-M. Resorcinol-formaldehyde based carbon aerogel: Preparation, structure and applications in energy storage devices. Microporous Mesoporous Mater. 2019, 279, 293-315. [CrossRef]

21. Raj kumar, T.; Gnana kumar, G.; Manthiram, A. Biomass-Derived 3D Carbon Aerogel with Carbon Shell-Confined Binary Metallic Nanoparticles in CNTs as an Efficient Electrocatalyst for Microfluidic Direct Ethylene Glycol Fuel Cells. Adv. Energy Mater. 2019, 9. [CrossRef]

22. Tanaka, N.; Kobayashi, H.; Nakanishi, K.; Minakuchi, H.; Ishizuka, N. Monolithic LC columns. Anal. Chem. 2001, 73, 420A-429A. [CrossRef] [PubMed]

23. Liang, C.; Dai, S.; Guiochon, G. A graphitized-carbon monolithic column. Anal. Chem. 2003, 75, 4904-4912. [CrossRef]

24. Al-Muhtaseb, S.A.; Ritter, J.A. Preparation and Properties of Resorcinol-Formaldehyde Organic and Carbon Gels. Adv. Mater. 2003, 15, 101-114. [CrossRef] 
25. Antoniou, E.; Alexandridis, P. Polymer conformation in mixed aqueous-polar organic solvents. Eur. Polym. J. 2010, 46, 324-335. [CrossRef]

26. Holmqvist, P.; Alexandridis, P.; Lindman, B. Phase Behavior and Structure of Ternary Amphiphilic Block Copolymer-Alkanol-Water Systems: Comparison of Poly(ethylene oxide)/Poly(propylene oxide) to Poly(ethylene oxide)/Poly(tetrahydrofuran) Copolymers. Langmuir 1997, 13, 2471-2479. [CrossRef]

27. Thubsuang, U.; Ishida, H.; Wongkasemjit, S.; Chaisuwan, T. Self-formation of 3D interconnected macroporous carbon xerogels derived from polybenzoxazine by selective solvent during the sol—Gel process. J. Mater. Sci. 2014, 49, 4946-4961. [CrossRef]

28. Qin, G.; Guo, S. Preparation of RF organic aerogels and carbon aerogels by alcoholic sol—Gel process. Carbon 2001, 39, 1935-1937. [CrossRef]

29. Palapati, N.K.R.; Demir, M.; Harris, C.T.; Subramanian, A.; Gupta, R.B. Enhancing the electronic conductivity of Lignin-sourced, sub-micron carbon particles. In Proceedings of the 2015 IEEE Nanotechnology Materials and Devices Conference (NMDC), Anchorage, AK, USA, 13-16 September 2015; pp. 1-2. [CrossRef]

30. Ashourirad, B.; Demir, M.; Smith, R.A.; Gupta, R.B.; El-Kaderi, H.M. Rapid transformation of heterocyclic building blocks into nanoporous carbons for high-performance supercapacitors. RSC Adv. 2018, 8, 12300-12309. [CrossRef]

31. Altinci, O.C.; Demir, M. Beyond Conventional Activating Methods, a Green Approach for the Synthesis of Biocarbon and Its Supercapacitor Electrode Performance. Energy Fuels 2020, 34, 7658-7665. [CrossRef]

32. Liu, H.; Cao, K.; Li, W.; Han, Q.; Zheng, R.; Shu, J.; Zhang, Z.; Huang, K.; Jing, Q.; Jiao, L. Constructing hierarchical $\mathrm{MnO}_{2} / \mathrm{Co}_{3} \mathrm{O}_{4}$ heterostructure hollow spheres for high-performance Li-Ion batteries. J. Power Sources 2019, 437. [CrossRef]

33. Wang, Y.; Zou, L.; Huang, Q.; Zou, Z.; Yang, H. 3D carbon aerogel-supported PtNi intermetallic nanoparticles with high metal loading as a durable oxygen reduction electrocatalyst. Int. J. Hydrog. Energy 2017, 42, 26695-26703. [CrossRef]

34. Oh, J.H.; Su Jo, M.; Jeong, S.M.; Cho, C.; Kang, Y.C.; Cho, J.S. New synthesis strategy for hollow NiO nanofibers with interstitial nanovoids prepared via electrospinning using camphene for anodes of lithium-ion batteries. J. Ind. Eng. Chem. 2019, 77, 76-82. [CrossRef] 